NBER WORKING PAPER SERIES

\title{
EVALUATING THE EFFECTIVENESS OF CHILD SAFETY SEATS AND SEAT BELTS IN PROTECTING CHILDREN FROM INJURY
}

\author{
Steven D. Levitt \\ Joseph J. Doyle \\ Working Paper 12519 \\ http://www.nber.org/papers/w12519
NATIONAL BUREAU OF ECONOMIC RESEARCH
1050 Massachusetts Avenue
Cambridge, MA 02138
September 2006

We thank Paul Heaton and Jesse Shapiro for their comments. Ethan Lieber provided outstanding research assistance. Financial support was provided by the National Science Foundation and the Sherman Shapiro Research Fund. Addresses: Steven Levitt, Department of Economics, University of Chicago, 1126 E. 59th Street, Chicago, IL 60637, slevitt@uchicago.edu; Joseph Doyle, Sloan School, MIT, Cambridge, MA 02142, jjdoyle@ mit.edu. The views expressed herein are those of the author(s) and do not necessarily reflect the views of the National Bureau of Economic Research.

(C) 2006 by Steven D. Levitt and Joseph J. Doyle. All rights reserved. Short sections of text, not to exceed two paragraphs, may be quoted without explicit permission provided that full credit, including (C) notice, is given to the source. 
Evaluating the Effectiveness of Child Safety Seats and Seat Belts in Protecting Children from Injury

Steven D. Levitt and Joseph J. Doyle

NBER Working Paper No. 12519

September 2006

JEL No. K2,R4

\begin{abstract}
Young children are required to use child safety seats, and the age threshold at which children can legally graduate to seat belts has steadily increased. This paper tests the relative effectiveness of child safety seats, lap-and-shoulder seat belts, and lap belts in preventing injuries among motor vehicle passengers aged 2-6. We analyze three large, representative samples of crashes reported to police, as well as linked hospital data. We find no apparent difference in the two most serious injury categories for children in child safety seats versus lap-and-shoulder belts. Child safety seats provide a statistically significant $25 \%$ reduction in the least serious injury category. Lap belts are somewhat less effective than the two other types of restraints, but far superior to riding unrestrained.
\end{abstract}

Steven D. Levitt

Department of Economics

University of Chicago

1126 East 59th Street

Chicago, IL 60637

and NBER

slevitt@midway.uchicago.edu

Joseph J. Doyle

MIT Sloan School of Management

50 Memorial Drive

E52-447

Cambridge, MA 02142

and NBER

jjdoyle@mit.edu 


\section{Introduction}

Motor vehicle crashes in the U.S. result in over 45,000 deaths and an estimated 2.4 million disabling injuries each year (NSC, 2006). Restraint systems such as seat belts and airbags have been shown to dramatically limit the injuries sustained in a crash (Kahane, 1986). For young children, all states currently require the use of child safety seats, and the minimum age and weight requirements to graduate to seat belts has been increasing over time (Insurance Institute for Highway Safety, 2004). Since 2003, more than a dozen states raised these requirements.

Two important drawbacks of child safety seats are their cost and difficulty of correct installation. The 1997 Census of Manufactures reported that consumers in the U.S. spend over $\$ 300$ million on roughly four million child safety seats each year. Meanwhile, it is estimated that $80 \%$ of child safety seats are incorrectly installed (US DOT, 1996), reducing the safety benefits provided by child safety seats (Kahane, 1986).

Seat belts offer a low-cost alternative to restrain children. All modern passenger vehicles come equipped with seat belts. Thus, there is no marginal cost to the consumer associated with their use. On the other hand, seat belts are primarily designed to fit adult passengers. Shoulder belts may fall improperly across the child's neck, and the lap belt may lie on the child's abdomen rather than across the hips, leading to possible abdominal injury and what is known as "seat belt syndrome". In spite of these important drawbacks of seat belts for children, previous research has documented that children restrained by seat belts fare much better in crashes than unrestrained children (Partyka, 1988; Johnston, Rivara, and Soderberg, 1994; Hertz, 1996).

\footnotetext{
${ }^{1}$ See, for example, Kulowski and Rost, 1956; Garrett and Braunstein, 1962; Agran, Dunkle, and Winn, 1987; Winston et al., 2000; Durbin, Arbogast, and Moll, 2001; and Arbogast et al. 2002.
} 
There is a surprisingly limited body of research assessing the relative efficacy of child safety seats and seat belts, and the existing studies come to very different conclusions. In a series of papers utilizing a large sample of parental reports of injuries among children aged 4-7, belt-positioning booster seats (the dominant form of child safety seat for this age group) have been found to reduce significant injuries by approximately 60\% relative to seat belts (Winston et al., 2000; Durbin et al., 2003). Levitt (2005) utilizes police report data for crashes with at least one fatality and finds no statistically significant difference in fatalities or injuries between child safety seats and lap-and-shoulder belts for children in this age range. ${ }^{2}$ That data set is far from ideal for studying injuries, however, as less than $2 \%$ of crashes with injuries involve a fatality.

In this paper, we undertake the first comparison of the effectiveness of child safety seats and seat belts based on representative samples of all crashes reported to the police. We utilize three different data sets: (1) the General Estimates Survey (GES), a nationally representative sample of approximately 50,000 crashes each year for sixteen years; (2) New Jersey Department of Transportation (NJDOT) data covering all crashes in that state between 2001 and 2004, and (3) a Wisconsin data set that not only includes the universe of crashes with police reports in that state from 1994 to 2002, but also links these crashes to hospital discharge records. Using these data, we are able to exploit the wealth of information in police reports, as well as within-vehicle and within-accident variation in restraint use, to compare seat belts and child safety seats in preventing injury. The results suggest that lap-and-shoulder seat belts perform as well as child safety seats in preventing serious injury for children aged 2 through 6 . Safety seats are associated

\footnotetext{
${ }^{2}$ Elliot et al. (2006), which combines the fatal accident data with another data set, the National Highway Traffic Safety Administration's National Automotive Sampling System Crashworthiness Data System, challenges the Levitt (2005) conclusions.
} 
with a statistically significant reduction in the least serious injury category. According to our estimates, if every child wearing a lap-and shoulder seat belt had instead been in a child safety seat, the number of injuries in this least serious category would be reduced by roughly $25 \%$. Lap belts are somewhat less effective than the two other types of restraints, but far superior to riding unrestrained.

The structure of the paper is as follows. Section two describes the data sources and provides some summary statistics. Section three describes the empirical strategy and main results. Section four offers some conclusions and interprets the results in terms of the estimated benefits of injury reduction compared to the costs of increased safety seat use.

\section{Data \& Summary Statistics}

The data used are from three government collected, publicly available data sets: the General Estimates Survey (GES), data from the New Jersey Department of Transportation (NJDOT), and the Wisconsin Crash Outcome Data Evaluation System (CODES).

The GES is a nationally representative, stratified sample of all crashes reported to the police, collected annually by the National Highway Transportation Safety Administration (NHTSA) for the period 1988-2004. Roughly 50,000 crashes are sampled each year. In all statistics and analyses reported in this paper, the sample weights provided in the GES are used to make our estimates representative of the estimated 6.4 million crashes involving an injury or significant property damage that occur annually. 
NJDOT data include all motor vehicle crashes reported to the police in New Jersey over the period 2001-2004. One advantage of the New Jersey data is its large size despite the fewer years available: more than 3.2 million people were involved in the 1.3 million police-reported crashes during these years.

Wisconsin CODES includes the universe of police accident reports from 19942002. These data have been linked to hospital discharge records by the University of Wisconsin's Center for Health Systems Research and Analysis (CHSRA). During these nine years, the system includes police reports for over 3.2 million people and 2.1 million vehicles. CHSRA estimates that $80 \%$ of all crash-related hospitalizations were linked successfully, and the linkage rate does not vary systematically with the type of restraint used. $^{3}$

For each of these data sets, the sample analyzed was restricted to children aged 26. Few children below the age of 2 use seat belts and few children over the age of 6 use child safety seats in our data. We also restrict the samples to children riding in passenger vehicles. ${ }^{4}$ Children riding in vehicle model years built prior to 1970 are excluded to ensure the presence of seat belts. Finally, approximately $10 \%$ of the data across the three sources are excluded due to missing values for restraint system used or the age of the passenger. The remaining samples include 46,205 observations in the GES (representing 5.5 million children applying the sampling weights), 74,971 observations in New Jersey, and 76,343 observations in Wisconsin.

\footnotetext{
${ }^{3}$ Emergency department admissions are available in Wisconsin CODES for 2002 and match the policereported injury rates.

${ }^{4}$ The precise classification of vehicle types differs across the data sets. We include children riding in cars, minivans, and SUV's in the GES data, passenger cars and trucks in the Wisconsin data, and cars, vans, and SUV/trucks in the New Jersey data.
} 
Passengers are recorded in police reports as using no restraint, a child safety seat, a lap-and-shoulder belt, shoulder-belt only, or lap-belt only. No distinction is made in the data with respect to the precise type or model of child safety seat (e.g. backless versus backed booster seats), and the data do not report whether a restraint was properly installed. We combine the small number of shoulder-only occupants with those wearing lap belts into a category we simply call "lap only", though the results are similar regardless of how the shoulder-only occupants are categorized.

All three data sets use the $\mathrm{KABC}$ scale of injury severity, although different names are given to the $\mathrm{A}, \mathrm{B}$, and $\mathrm{C}$ injury categories in the data sets. In the GES and Wisconsin CODES, these four injury categories in order of decreasing severity are: fatal, incapacitating, nonincapacitating, and possible injury. In the NJDOT data, the four injury categories are labeled as: fatal, incapacitating, moderate, and complaint of pain. In all three data sets, the fatality rates are extremely low. Thus, in the analysis that follows, fatal and incapacitating injuries were combined into a single category of injury to provide a more precise estimate of the effectiveness of restraints in reducing the most severe injuries.

\section{Summary Statistics}

Summary statistics for the GES data set are reported in Table $1 .^{5}$ Means for the full sample and each of the restraint types are included. Children in safety seats differ from other children in two important dimensions. Those riding in child safety seats are substantially younger on average than children using seat belts or riding unrestrained.

\footnotetext{
${ }^{5}$ For reasons of space, we do not report detailed summary statistics for the other two data sets. They are similar to the GES, with the exception that the New Jersey and Wisconsin data sets only include crashes from more recent years, and thus are dominated by more recent vehicle model years, fewer children riding in the front seat, and fewer children unrestrained.
} 
Children in safety seats are also much less likely to be in the front seat than those using lap-and-shoulder belts, reflecting the availability of this type of restraint in front seats. Unrestrained children are also more likely to be found in the front seat. In all three data sets, we can reject equality of restraint use by seat position at the .01 level. Controlling for these factors is potentially quite important when estimating the effectiveness of restraints. Larger, older passengers have been shown to sustain greater injuries in crashes (Starnes, 2005), and riding in the front seat is associated with a substantially elevated risk of injury (Kahane, 2004; Starnes 2005).

Other than the differences in age and seat location, children in child safety seats and lap-and-shoulder belts have similar summary statistics, with some notable differences from those who are unrestrained or wearing lap-belts. Lap-belt wearing children and those who are unrestrained are more likely to be riding in older model cars, and thus will derive less benefit from recent vehicle safety advances (Kahane, 2004). Children with no restraint also appear to be in vehicles with riskier drivers in general: the driver is less likely to be wearing a seat belt, more likely to be at fault in the crash, and more likely to be involved in a one-vehicle crash. Driver injuries are similar across the three types of restraints, but drivers of unrestrained children are found to suffer worse injuries, possibly because these drivers are more likely to be themselves unrestrained.

\section{Estimating the relative effectiveness of child safety seats and seat belts}

The top panel of Table 2 presents the raw data on injury rates across restraint types for the three data sources. Rates of injury are substantially higher for unrestrained passengers. The differences between unrestrained passengers and those using any of the 
three restraints are highly statistically significant for all injury categories in all of the data sets. Injury rates for children wearing seat belts are also somewhat higher compared to children in child safety seats.

The raw data on injury rates across restraint types may be misleading, however, given the differences across other observable characteristics. As noted earlier, one important factor to control for is seating position. The bottom panel of Table 2 also reports raw injury rates, but restricts the comparison to children riding in the back of the vehicle. The differences in outcomes between those in child seats and those in seat belts fall (and in some cases disappear completely) when the sample is restricted to back-seat passengers. The largest differences that persist are for the least serious injury category ("possible injury"). Riding unrestrained continues to be highly correlated with injury when the sample is limited to back seat passengers.

Seating position is, of course, just one of many factors that can contaminate measurement of the effectiveness of the various restraints. We use regression analysis to control for a wide range of potential confounding variables. In all cases, regressions are estimated using linear probability models. Probit models, evaluated at the sample mean, yield similar implied effects. The particular specification we estimate for child $i$ involved in a crash in year $t$ riding in a vehicle from model year $m$, is as follows:

(1) $Y_{i}=R_{i} \alpha+X_{i} \beta+\delta_{t}+\eta_{m}+\varepsilon_{i}$

where $Y$ is an indicator for a fatal or incapacitating injury, a nonincapacitating injury, or possible injury in three separate regressions. These injury categories are mutually exclusive and exhaustive. $R$ represents a vector of indicator variables describing the restraint type used, with child safety seats as the omitted category to test the difference in 
injury rates compared to a lap-and-shoulder belt, a lap belt, and a lack of restraint. $X$ represents the control variables listed in Table 1: indicators for the age of the child, the principle point of impact in the crash, the time of day (early morning, daytime, and evening), whether the crash occurred on a weekend, the number of vehicles involved, whether the posted speed limit was 55 miles per hour and above, and the type of vehicle (e.g. car, minivan, or SUV/truck). Driver injuries, seat belt status, and the interaction between the driver injuries and seat belt status are also included as controls. $\delta_{t}$ is a vector of year dummies, and $\eta_{m}$ is a vector of model year dummies. We also estimate models in which accident or vehicle fixed effects are included.

We present the results of this estimation on each of the three data sets in Tables 35. Table 3 reports the main results using the nationally representative GES database. Only the coefficients on the restraint types are included in the tables. Full regression results are available on request from the authors. ${ }^{6}$ There are three sets of columns corresponding to the three outcomes: fatal or incapacitating injury, nonincapacitating injury, and possible injury. For each outcome, the results are presented for models with no controls, a second column that reports the results of models with seat location indicators, and a third column that includes the full set of controls.

The dependent variable in the first three columns of Table 3 is a fatal or incapacitating injury. As noted above, the omitted restraint category is child safety seats, so all estimates reported are relative to that category. Absent any controls (column 1), children wearing seat belts have somewhat higher rates of these injuries than those in child safety seats. Unrestrained children are much more likely to suffer fatal or

\footnotetext{
${ }^{6}$ The coefficients on these control variables are as expected. Riding in the front seat, for instance, greatly raises the risk of serious injury. The safest seat location, all else equal, is the back middle seat.
} 
incapacitating injuries. After controlling for seat position in column 2, the negative point estimate on lap-and-shoulder belts implies that children using this device actually experience a (small and statistically insignificant) reduction in fatal and incapacitating injuries relative to children in child safety seats. Controlling for seat position does not substantially affect the coefficients on lap-only belts or those who are unrestrained. Adding the full set of controls in column 3 leads the lap-and-shoulder belt coefficient to once again become positive (though statistically insignificant), doubles the coefficient on lap-only belts, and cuts in half the estimate for unrestrained passengers. ${ }^{7}$ Using our preferred estimates in column 3, relative to riding unrestrained, lap-and-shoulder belts provide 94 percent of the protection of child safety seats for fatal or incapacitating injuries. ${ }^{8}$ Lap-only belts provide 87 percent of the protection of child safety seats in this injury category.

Columns 4-6 report parallel results for the second most severe injury category: nonincapacitating injuries. As more controls are added, the gap between child safety seats and the other categories falls. In the full specification, there is no statistically significant difference between children in lap-and-shoulder belts and those in child safety seats; for lap-only belts the estimates are statistically significant. Relative to riding

\footnotetext{
${ }^{7}$ The driver injury categories exert the strongest influence among the controls. This reflects the fact that driver injuries are good proxies for the level of accident severity, though it may also reflect correlated measurement error. That is, measurement error in the child's injury report and seat belt status may be correlated with measurement error in the driver injury report and driver seat belt status, especially since they are recorded by the same officer. Depending on whether and how this measurement error is related to the officer's reporting of restraint types, it can bias the estimation in either direction. It is worth noting that omitting the driver injury measures does not systematically affect the estimates on restraint types.

${ }^{8}$ Using a lap-and-shoulder belt increases these injuries by .0015 relative to child safety seats, compared to an increase of .0265 for riding unrestrained. The ratio of the coefficients on lap-and-shoulder belts and no restraint is approximately $.06(.0015 / .0265)$, implying that lap-and-shoulder belts provide 94 percent of the benefits of child safety seats $(1-.06=.94)$.
} 
unrestrained, a lap-and-shoulder belt provides 97.5 percent of the benefit of a child safety seat and a lap-only belt yields 83 percent of the benefit.

Columns 7-9 present results for the least serious injury category: possible injury. The patterns are similar to nonincapacitating injuries, except that child safety seats are now statistically significantly better than all of the other devices. Both types of seat belts provide only about two-thirds of the benefits of child safety seats in preventing these least serious injuries.

Table 4 is identical in structure to Table 3, except that the results are based on the NJDOT data set rather than the GES. The patterns observed in the New Jersey data are quite similar to those in the GES. Adding controls tends to diminish the implied benefit of child safety seats. The point estimates suggest that lap-and-shoulder belts are 98 percent as effective as child safety seats for the most serious injuries (with the difference not statistically significant), 94 percent as effective for moderate injuries, and 83 percent as effective for the most minor injury category. In all three categories, lap-only belts are less effective than lap-and-shoulder belts.

Table 5 reports the same specifications, but using the Wisconsin data. The results are similar to the other data sets, except that now with the full set of controls, lap-andshoulder belts carry a point estimate that implies they are (statistically insignificantly) better at preventing the two most serious injury types. The implied effectiveness of lapand-shoulder belts relative to child safety seats in this sample is 105 percent, 103 percent, and 90 percent for the three injury categories. Lap-only belts are estimated to be 96 percent, 96 percent, and 85 percent as effective as child safety seats. 
The consistency across the three data sets increases our confidence in the findings. There appears to be only minor differences between child safety seats and lapand-shoulder belts in preventing fatal, incapacitating, and nonincapacitating injuries. Only for the least serious category of injuries do we consistently observe substantial improvements from child safety seats relative to lap-and-shoulder belts, with these benefits ranging from 10-38 percent depending on the data set.

Because the Wisconsin crash data are linked to hospital discharge records, for that data set we are able to explore a wider set of outcome variables, as shown in Table 6 . In the first two columns of the table, the dependent variable is an indicator equal to one if a child in a crash is admitted to the hospital and equal to zero otherwise. Hospital admission represents inpatient care associated with more serious injuries, as opposed to just a visit to the emergency department. With or without controls, the point estimate on the lap-and-shoulder belt category is very close to zero and statistically insignificant, implying no difference in hospitalization rates for children in child safety seats and those using lap-and-shoulder belts. The coefficient for lap belts is also small and statistically insignificant, implying that out of every 700-800 children involved in a crash wearing a lap belt, only one fewer hospital admission would have occurred if those children were using child safety seats. In stark contrast, unrestrained passengers are 5 times more likely to be hospitalized compared to children using child safety seats or lap-and-shoulder belts.

The Wisconsin CODES data also provide measures of injury severity for those admitted to the hospital, summarized by the patient's length of stay and hospital charges. ${ }^{9}$

\footnotetext{
${ }^{9}$ The Wisconsin data also allow us to look by location of the injury on the body. Lap-and-shoulder belts and child safety seats yield similar rates for injuries to the head, neck, and spine - those injuries most related to hospital charges and mortality. Lap belts are associated with slightly higher rates of head injury, and both types of belts were associated with slightly higher rates of leg injury.
} 
Greater treatment levels are positively correlated with police reported injury severity and mortality.

The next four columns of Table 6 provide estimates of treatment differences across restraint types, conditional on hospital admission. The models are similar to equation (1), with the natural logarithm of each treatment variable as the dependent variable. ${ }^{10}$ With the smaller sample size, these estimates become relatively imprecise and the point estimates suggest that child safety seats are associated with worse injuries compared to seat belts. This (insignificant) difference is found for the comparison of safety seats and unrestrained passengers as well, which may reflect worse accidents required to induce a hospital admission for children in safety seats who are much less likely to be admitted into the hospital compared to children with no restraint. Restraint Types \& Accident Severity

One issue that arises when comparing injury rates is that the accident severity may vary across restraint types. Parents with a relatively high degree of risk aversion may be more likely to use safety seats and drive more safely. For example, while not a general result, de Meza and Webb (2001) and Jullien, Salanie, and Salanie (1999) suggest that individuals with a high degree of risk aversion may invest in self protection as well as market insurance. Their results also suggest that careful driving behavior and restraint use may be complements. This would lead to an upward bias in the difference in injury rates between those wearing seat belts and those in safety seats. Indeed, as was noted earlier in Table 1, unrestrained children were more likely to be in vehicles where the driver is at fault and in a one-vehicle crash, though similar means were found for

\footnotetext{
${ }^{10}$ The natural logarithm transformation provides more precise estimates, reflecting the skewed nature of hospital treatment data. Similar results are found for alternative functional forms. Results were also similar when the child's insurance status was included in these specifications.
} 
restrained passengers regardless of type. On the other hand, modes of self protection may be substitutes, as in Peltzman (1975). Better protected riders may afford the driver the ability to take more risks on the road. This would lead to a downward bias in the above results.

One approach to control for the accident severity is to include accident or vehicle fixed effects in the regression. These fixed effects will also absorb other unobserved sources of variation that may be contaminating the estimates, such as driving ability, road conditions, and the likelihood of the police officer to record particular types of injuries and restraint use. There are two drawbacks from using within-vehicle or within-accident variation in restraint use and injuries. First, less data can be used: only vehicles or accidents with more than one child involved provide variation in such a specification. Second, it relies on children using different types of restraints in the same vehicle or accident. Within a vehicle, especially, there is relatively little variation in restraint use and the variation that is present is closely tied to the age of the children. Concerns about the endogeneity of restraint type choice become heightened (e.g. if a parent puts one 4 year old in a child safety seat and another in a seat belt, that may reflect children of different weights, despite their similar ages). Concerns about coding errors in the data also increase: as almost all of the variation is being removed from the data with vehicle fixed effects, a greater fraction of the variation that remains may be due to mistakes in the data.

With these caveats in mind, Table 7 reports the results of the fixed-effects specifications, where each panel is devoted to a particular data source. The three sets of columns again relate to the three different injury outcome variables. Specifications with 
accident fixed effects and vehicle fixed effects are reported in the odd and even columns respectively. All models include full controls, although most of those reported in Table 2 are absorbed by the fixed effects. Age, seat location, and sex, are used in the vehicle fixed effects models, and indicators for model year, point of impact, vehicle type, and driver controls are also included in the accident fixed effects specification.

Because there are fewer observations involving multiple children in the same vehicle or accident, the results are relatively less precisely estimated. Nevertheless, the point estimates continue to show small differences for serious injuries. Estimated differences in the effectiveness of seat belts versus child safety seats for the least severe injury category are much smaller when accident or vehicle fixed effects are included for all three data sets. In the GES data, lap-and-shoulder belts have a coefficient of .0183 in the specification with full controls for the least severe injuries in Table 3, compared to a coefficient of .0108 when accident fixed effects are included - an increase in the relative effectiveness of lap-and-shoulder belts from 62 percent to 82 percent. For the New Jersey data, that same comparison yields .017 without accident fixed effects and .0067 with accident fixed effects ( 82 percent vs. 90 percent).

Table 8 explores the sensitivity of the basic results to various subgroups of the data. Because of space considerations, we limit the tabular presentation to the GES data set. The results are similar in the other data sets. The three panels correspond to the injury categories; the columns correspond to the different subgroups. ${ }^{11}$ The results are generally robust across the subgroups, though the smaller sample sizes result in less

\footnotetext{
${ }^{11}$ Mean injury rates are in the bottom row of each panel. Injury rates are found to increase with age, as found in previous research. Injuries are somewhat lower for vehicles with model years more recent than 1996, a period when over $80 \%$ of children wearing a seat belt in the back left or back right of a vehicle used the lap-and-shoulder variety. Passenger cars have somewhat higher injury rates, likely attributable to their lower weight compared to minivans and SUVs.
} 
precise estimates. In terms of lap-and-shoulder belts, for none of the subgroups can we reject that the coefficients are equal to zero for the two most serious injury categories. For possible injuries, we can reject equality for every subgroup except the older age groups. For lap-only belts, about half of the coefficients across subgroups are statistically significant. Combining the information across injury severity levels, there does not appear to be strong evidence that the relative effectiveness of seat belts versus child safety seats differs sharply across the subgroups examined. ${ }^{12}$

\section{Conclusion}

This study provides the first analysis of the relative effectiveness of seat belts and child safety seats in preventing injury based on representative samples of police-reported crash data. Our evidence suggests that lap-and-shoulder seat belts perform roughly as well as child safety seats in preventing serious injury for older children, although safety seats tend to be better at reducing less serious injuries. Lap belts had somewhat higher injury rates, while no restraint is associated with much larger injury rates. These results are robust to controls for accident severity, including within-vehicle and within-accident comparisons, as well as across age, seat location, and model year subgroups. Data on

\footnotetext{
${ }^{12}$ Although not shown in tabular form, we have also investigated the relative effectiveness of the various restraints by the seriousness of the accident. To proxy for how serious the accident is, we used the sample of over 300,000 passengers aged seven and above in the GES to estimate specifications like those in equation (1) with a dependent variable of fatal or incapacitating injury. Age fixed effects were used to control for age, and the coefficients on all non-age controls were used to predict (out of sample) the likelihood of serious injury for passengers aged 2-6 based on their characteristics, such as crash angle, seat location. We then divided individuals into five quintiles according to the predicted likelihood of serious injury. All of the estimates were somewhat imprecise. The only statistically significant difference we observed between child safety seats and lap-and-shoulder belts for the two most serious injury categories were for the least severe quintile of crashes, where lap-and-shoulder belts are 80 percent as effective for both injury categories. The top four quartiles showed injury differences only for the least serious injury category.
} 
hospital admissions, length of stay, and hospital charges confirm the results based on police reported injuries.

These comparisons across restraint types incorporate the way they are used (or misused) in practice. Because many child safety seats are, in actual use, improperly installed, our estimates are likely to understate the benefits associated with proper use of child safety seats. From a public policy perspective, however, understanding how safety devices work in practice, as opposed to under ideal circumstances, is of great importance.

These estimates of the benefits of child safety seats, which are based on samples reflecting all crashes reported to police in the areas represented, are far below those obtained in prior studies based on parent interviews. Even the upper bound estimates of the 95 percent confidence intervals that we estimate are much smaller than the benefits found in earlier studies using a survey-based approach.

Understanding why the results obtained from different sampling approaches vary so sharply is an important question. One possibility is that either parents (in the previous studies) or police (in the current study) systematically misreport restraint use or injuries. The congruence between police reports and hospital charges in the Wisconsin data provide external validation of the police codings. In addition, misreports to police would likely result in children being recorded as belted when they were actually unrestrained at the time of the crash. This type of misreporting would lead to an upward bias in the estimates presented here, and thus is unlikely to explain the differing results. A second possibility is that we include a richer set of control variables than prior research. The three data sets we examine show large differences in injury rates in the raw data between 
children in child safety seats and in seat belts. After controlling for a wide range of factors, however, the differences shrink dramatically or disappear.

The results allow an estimate of the cost effectiveness of an investment in child safety seats that are increasingly mandated for older children. In 1994, the Federal Highway Administration estimated monetary values associated with injuries on the KABC scale (Judycki, 1994). The only category for which we observe systematic differences between child safety seats and lap-and-shoulder belts is the C category. Corrected for inflation between 1994 and 2004 using the Consumer Price Index, the current dollar value associated with this category of injury is $\$ 24,130 .^{13}$ This type of injury is roughly $25 \%$ higher among children using lap-and-shoulder belts relative to those in child safety seats. If every child aged 2-6 that was using a child safety seat instead switched to a lap-and-shoulder belt, the predicted increases in the number of $\mathrm{C}$ injuries in the United States in 2004 would have been approximately 3,000. The implied dollar value of these changes in injuries is $\$ 72$ million, below the roughly $\$ 200$ million spent annually by consumers on child safety seats for children aged 2-6, but on the same order of magnitude. To the extent that there are extra benefits (albeit statistically insignificant ones in our analysis) of car seats in preventing more serious injuries, this estimate represents a lower bound on the safety value of car seats. This cost benefit calculation is, of course, incomplete because it ignores other benefits (such as comfort for the child) and costs (parental time installing the seats) that accompany car seats.

\footnotetext{
${ }^{13}$ The National Safety Council's Economics and Data Resource Center reports an estimated cost of these injuries due to wage and productivity losses, medical expenses, administrative expenses, motor vehicle damage, employers' uninsured costs, and a measure of the value of lost quality of life of $\$ 22,900$ in 2004 (NSC, 2004).
} 
Nevertheless, the benefits of child safety seats in these three data sets is far less than implied by previous studies relying on parental survey data. 


\section{References}

Agran P, Dunkle D, Winn D. Injuries to a sample of seat belted children evaluated and treated in a hospital emergency room. Journal of Trauma 1987; 2:58-64.

Arbogast KB, Durbin DR, Kallan MJ, Menon RA, Lincoln AE, Winston FK. The role of restraint and seat position in pediatric facial fractures. Journal of Trauma 2002; 52: 693-8.

Durbin DR, Arbogast KB, Moll EK. Seat belt syndrome in children: a case report and review of the literature. Pediatric Emergency Care 2001;17:474-7.

Durbin D, Elliot M, Winston F. Belt-positioning booster seats and reduction in risk of injury among children in vehicle crashes. JAMA 2003; 289: 2835-2840.

Elliott, Michael R., Kallan, Michael J., Durbin, Dennis R., and Flaura K. Winston. Effectiveness of Child Safety Seats vs Seat Belts in Reducing Risk for Death in Children in Passenger Vehicle Crashes. Archives of Pediatrics \& Adolescent Medicine. 2006;160:617-621

Garrett JW, Braunstein PW. The seat belt syndrome. Journal of Trauma 1962;2:220-8.

Hertz E. Revised estimates of child restraint effectiveness. Washington, D.C.: National Highway Traffic Safety Administration, 1996.

Insurance Institute for Highway Safety, 2004. "Child Restraint, Belt Laws as of July 2004," as posted on www.highwaysafety.org/safety_facts/state_laws/restrain.htm.

Johnston C, Rivara FP, Soderberg R. Children in Car Crashes: Analysis of Data for Injury and Use of Restraints. Pediatrics 1994; 93:960-5.

Judycki DC. Motor vehicle accident costs. Federal Highway Administration. 1994. Available at http://www.fhwa.dot.gov/legsregs/directives/techadvs/t75702.htm. Accessed August 23, 2005.)

Jullien, Bruno, Salanie, Bernard, and Francois Salanie. "Should More Risk-Averse Agents Exert More Effort?" The Geneva Papers on Risk and Insurance Theory, 24 (June 1999), 19-28.

Kahane C. An evaluation of child passenger safety: the effectiveness and benefits of safety seats. Washington, D.C.: National Highway Traffic Safety Administration, 1986. (Report no. DOT HS 806 890.)

-----. Lives saved by the federal motor vehicle safety standards and other vehicle safety technologies. Washington, D.C.: National Highway Traffic Safety Administration, 2004. (Report no. DOT HS 809 833.) 
Kulowski K, Rost W. Intra-abdominal injury from safety belts in auto accidents. Archives of Surgery 1956; 73:970-1.

Levitt S. Evidence that Seat Belts are as Effective as Child Safety Seats in Preventing Death for Children Aged Two and Up. NBER Working Paper No. 11591, 2005.

Meza, David de, and David C. Webb “Advantageous Selection in Insurance Markets," RAND Journal of Economics 32 (Summer 2001), 249-262.

National Highway Traffic Safety Administration. Booster seat study report to Congress. Washington, D.C.: NHTSA, 2005. Available at http://www-nrd.nhtsa.dot.gov/departments/nrd-11/childsafety/index.htm\#. Accessed August 25, 2005.

National Safety Council. Injury Facts. Itsaca, IL: NSC. 2006.

National Safety Council. Estimating the Costs of Unintentional Injuries, 2004. as posted on http://www.nsc.org/lrs/statinfo/estcost.htm.

Partyka S. Lives saved by child restraints from 1982 through 1987. Washington, D.C.: National Highway Traffic Safety Administration, 1988. (Report no. DOT HS 807 371.)

Peltzman, Sam. The Effects of Automobile Safety Regulation. The Journal of Political Economy 1975; 83(4):677-726.

Starnes, M. Child passenger fatalities and injuries, based on restraint use, vehicle type, seat position, and number of vehicles in the crash. Washington, DC: National Highway Traffic Safety Administration, 2005. (Report No. DOT HS 809 784.)

Winston FK, Durbin DR, Kallan M, Moll E. The danger of premature graduation to seat belts for young children. Pediatrics 2000; 105:1179-83. 
Table 1: Summary Statistics: GES Sample

\begin{tabular}{|c|c|c|c|c|c|c|c|}
\hline \multirow{2}{*}{\multicolumn{2}{|c|}{$\underline{\text { Characteristics }}$}} & \multicolumn{2}{|c|}{ Full Sample } & \multicolumn{4}{|c|}{ Means by Restraint Type } \\
\hline & & \multirow{3}{*}{$\begin{array}{l}\text { Mean } \\
\\
3.91 \\
0.51 \\
\end{array}$} & \multirow{3}{*}{$\begin{array}{c}\text { Std Dev } \\
\\
1.39 \\
0.50\end{array}$} & \multirow{3}{*}{$\begin{array}{c}\text { safety seat } \\
2.92 \\
0.51\end{array}$} & \multirow{3}{*}{$\begin{array}{c}\begin{array}{c}\text { lap and } \\
\text { shoulder }\end{array} \\
4.42 \\
0.50 \\
\end{array}$} & \multirow{3}{*}{$\begin{array}{c}\text { lap only } \\
\\
4.28 \\
0.50 \\
\end{array}$} & \multirow{3}{*}{$\begin{array}{c}\begin{array}{c}\text { no } \\
\text { restraint }\end{array} \\
4.12 \\
0.51 \\
\end{array}$} \\
\hline Child & age & & & & & & \\
\hline & boy & & & & & & \\
\hline Seat & front & 0.25 & 0.44 & 0.13 & 0.39 & 0.16 & 0.32 \\
\hline Location & back left & 0.25 & 0.43 & 0.30 & 0.23 & 0.25 & 0.17 \\
\hline & back middle & 0.14 & 0.35 & 0.17 & 0.06 & 0.23 & 0.17 \\
\hline & back right & 0.27 & 0.45 & 0.34 & 0.25 & 0.28 & 0.19 \\
\hline & back other & 0.005 & 0.07 & 0.002 & 0.001 & 0.006 & 0.018 \\
\hline & location unknown & 0.08 & 0.26 & 0.06 & 0.07 & 0.08 & 0.13 \\
\hline \multirow[t]{14}{*}{ Crash } & front impact & 0.42 & 0.49 & 0.42 & 0.43 & 0.41 & 0.44 \\
\hline & side impact & 0.30 & 0.46 & 0.29 & 0.31 & 0.31 & 0.31 \\
\hline & rear impact & 0.23 & 0.42 & 0.25 & 0.23 & 0.22 & 0.16 \\
\hline & other impact & 0.003 & 0.06 & 0.003 & 0.004 & 0.003 & 0.003 \\
\hline & missing impact & 0.04 & 0.21 & 0.03 & 0.03 & 0.05 & 0.09 \\
\hline & 1 vehicle & 0.12 & 0.32 & 0.12 & 0.10 & 0.12 & 0.18 \\
\hline & 2 vehicles & 0.76 & 0.43 & 0.74 & 0.78 & 0.78 & 0.71 \\
\hline & 3 or more vehicles & 0.12 & 0.33 & 0.13 & 0.12 & 0.11 & 0.11 \\
\hline & speed limit $>=55$ & 0.17 & 0.38 & 0.18 & 0.16 & 0.17 & 0.21 \\
\hline & speed limit missing & 0.13 & 0.34 & 0.16 & 0.10 & 0.15 & 0.11 \\
\hline & daytime & 0.89 & 0.31 & 0.91 & 0.90 & 0.88 & 0.85 \\
\hline & evening & 0.09 & 0.28 & 0.08 & 0.08 & 0.10 & 0.11 \\
\hline & early morning & 0.01 & 0.12 & 0.01 & 0.01 & 0.02 & 0.03 \\
\hline & weekend & 0.28 & 0.45 & 0.26 & 0.27 & 0.32 & 0.31 \\
\hline \multirow[t]{4}{*}{ Vehicle } & car & 0.68 & 0.47 & 0.64 & 0.68 & 0.70 & 0.71 \\
\hline & minivan & 0.13 & 0.34 & 0.16 & 0.13 & 0.11 & 0.10 \\
\hline & SUV & 0.19 & 0.39 & 0.20 & 0.19 & 0.18 & 0.19 \\
\hline & model year $>=1990$ & 0.53 & 0.50 & 0.66 & 0.60 & 0.48 & 0.25 \\
\hline \multirow[t]{8}{*}{ Driver } & driver belted & 0.91 & 0.29 & 0.48 & 0.96 & 0.98 & 0.96 \\
\hline & driver died & 0.0009 & 0.031 & 0.0054 & 0.0004 & 0.0004 & 0.0002 \\
\hline & driver incapacitated & 0.03 & 0.16 & 0.07 & 0.02 & 0.02 & 0.02 \\
\hline & driver non-incapacitated & 0.06 & 0.23 & 0.10 & 0.05 & 0.05 & 0.05 \\
\hline & driver possibly injured & 0.15 & 0.36 & 0.15 & 0.15 & 0.15 & 0.16 \\
\hline & driver no injury & 0.76 & 0.43 & 0.65 & 0.78 & 0.78 & 0.77 \\
\hline & driver at fault & 0.56 & 0.50 & 0.64 & 0.55 & 0.55 & 0.55 \\
\hline & Observations & 46205 & & 6072 & 13686 & 17519 & 8928 \\
\hline
\end{tabular}

The GES is a nationally representative sample of crashes from 1988 - 2004 available from NHTSA, and sampling weights are applied to calculate nationally representative means. 
Table 2: Injuries Across Restraint Types

\section{A. All Children 2-6 years old}

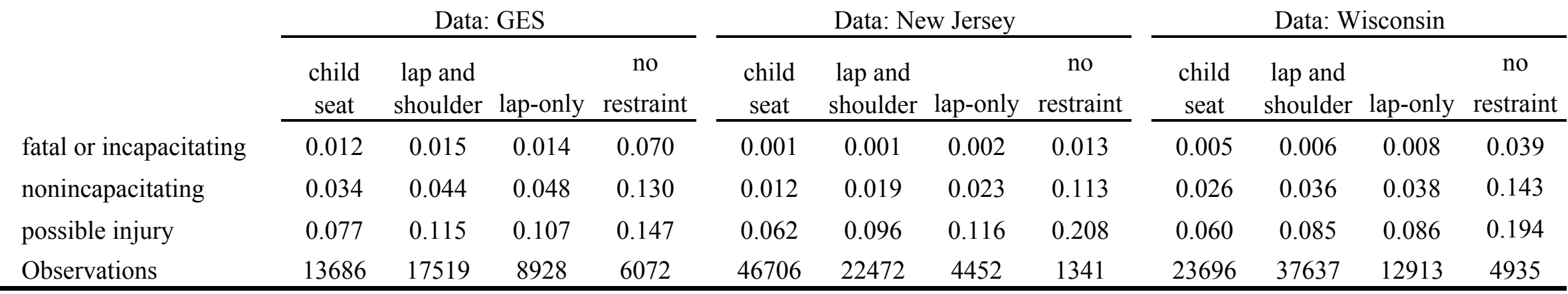

\section{B. Children 2-6 years old in back seat}

Data: GES

\begin{tabular}{|c|c|c|c|}
\hline $\begin{array}{l}\text { child } \\
\text { seat }\end{array}$ & $\begin{array}{l}\text { lap and } \\
\text { shoulder }\end{array}$ & lap-only & $\begin{array}{c}\text { no } \\
\text { restraint }\end{array}$ \\
\hline 0.011 & 0.011 & 0.013 & 0.061 \\
\hline 0.032 & 0.035 & 0.042 & 0.103 \\
\hline 0.075 & 0.108 & 0.105 & 0.142 \\
\hline 11976 & 10857 & 7509 & 4192 \\
\hline
\end{tabular}

Data: New Jersey

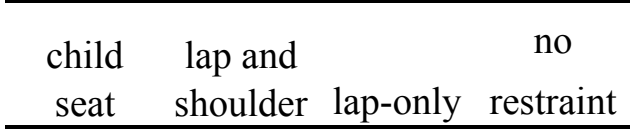

fatal or incapacitating

nonincapacitating

possible injury

Observations

\begin{tabular}{llll}
\hline 0.001 & 0.001 & 0.001 & 0.014 \\
0.012 & 0.017 & 0.023 & 0.109 \\
0.061 & 0.092 & 0.115 & 0.201
\end{tabular}

\begin{tabular}{cccc}
\multicolumn{4}{c}{ Data: Wisconsin } \\
\hline $\begin{array}{c}\text { child } \\
\text { seat }\end{array}$ & $\begin{array}{c}\text { lap and } \\
\text { shoulder }\end{array}$ & $\begin{array}{c}\text { no } \\
\text { lap-only }\end{array}$ & restraint \\
\hline 0.005 & 0.005 & 0.007 & 0.033 \\
0.025 & 0.028 & 0.033 & 0.111 \\
0.059 & 0.079 & 0.085 & 0.180 \\
20686 & 23685 & 11220 & 3385
\end{tabular}

The GES is a nationally representative sample of crashes from 1988 - 2004 available from NHTSA, and sampling weights are applied to calculate nationally representative means. The New Jersey Department of Transportation data contains all police-reported crashes in New Jersey from 2001 - 2004, and the injury severity categories are slightly differently labeled (fatal or incapacitating, moderate injury, and complaint of pain), although all three data sources use the KABC scale. The Wisconsin CODES data contain the universe of police-reported crashes in Wisconsin from $1994-2002$. 
Table 3: Injury Comparison Across Restraint Types: GES

Dependent Variable:

fatal or incapacitating

\begin{tabular}{ccc}
$(1)$ & $(2)$ & $(3)$ \\
\hline 0.0027 & -0.0002 & 0.0015 \\
{$[0.0011]^{*}$} & {$[0.0012]$} & {$[0.0013]$}
\end{tabular}

nonincapacitating

possible injury

lap \& shoulder

$\begin{array}{ccc}(4) & (5) & (6) \\ 0.0109 & 0.0026 & 0.0014\end{array}$

$[0.0020]^{* *} \quad[0.0021] \quad[0.0023]$

0.0017

0.0017

0.0034

0.0143

0.0136

0.0093

$[0.0025]^{* *}[0.0025]^{* *}[0.0028]^{* *}$

$\begin{array}{lll}0.0574 & 0.0560 \quad 0.0265\end{array}$

0.0967

0.0913

0.0558

$\frac{[0.0047]^{* *}[0.0047]^{* *}[0.0051]^{* *}}{\text { Nos }}$

\begin{tabular}{ccc}
$(7)$ & $(8)$ & $(9)$ \\
\hline 0.0378 & 0.0326 & 0.0183 \\
{$[0.0038]^{* *}$} & {$[0.0039]^{* *}$} & {$[0.0043]^{* *}$} \\
0.0295 & 0.0287 & 0.0170
\end{tabular}

$[0.0033]^{* *}[0.0033]^{* *}[0.0030]^{* *}$

Control for Seat Location

Full Controls

Observations

R-squared

\begin{tabular}{cccccc}
\hline No & Yes & Yes & No & Yes & Yes \\
No & No & Yes & No & No & Yes \\
\hline 46205 & 46205 & 46205 & 46205 & 46205 & 46205 \\
0.0162 & 0.0174 & 0.2791 & 0.017 & 0.0207 & 0.1239 \\
0.0201 & 0.0201 & 0.0201 & 0.0518 & 0.0518 & 0.0518
\end{tabular}

$[0.0046]^{* *}[0.0046]^{* *}[0.0049]^{* *}$

$\begin{array}{lll}0.0700 & 0.0646 \quad 0.0476\end{array}$

$[0.0060]^{* *}[0.0061]^{* *}[0.0071]^{* *}$

Mean of Dep. Var.

0.020

0.0518

0.0518

$0060]^{* *}$

$\begin{array}{cc}\begin{array}{c}\text { Yes } \\ \text { No }\end{array} & \text { Yes } \\ \text { Yes }\end{array}$

Full controls include indicators for each age, seating position in the vehicle, principle point of impact, the number of vehicles in the crash, the type of vehicle, the time of the crash, whether it was on a weekend, if the speed limit was greater than $55 \mathrm{mph}$, year, model year, as well as indicators for missing values for the seat location, speed limit,

time of day, day of week, and model year. Driver controls include whether the driver was belted, the degree of injury sustained by the driver, interactions between the driver belt status and driver injuries, and whether the driver was at fault. Excluded category is child safety seat. Sampling weights are applied to calculate nationally representative statistics. $*=$ significant at $5 \%$ level; $* *=$ significant at $1 \%$ level. 
Table 4: Injury Comparison Across Restraint Types: New Jersey

Dependent Variable:

fatal or incapacitating

$$
\text { (1) }
$$

0.0004

$$
\text { (2) }
$$

\begin{tabular}{ccc}
{$[0.0002]$} & {$[0.0002]$} & {$[0.0002]$} \\
\hline 0.0018 & 0.0018 & 0.0017
\end{tabular}

(3)

\begin{tabular}{ccc}
\hline 0.0018 & 0.0018 & 0.0017 \\
{$[0.0008]^{*}$} & {$[0.0007]^{*}$} & {$[0.0007]^{*}$} \\
\hline 0.0128 & 0.0124 & 0.0108
\end{tabular}

$\underline{[0.0031]^{* *}[0.0032]^{* *}[0.0030]^{* *}}$

no restraint

\begin{tabular}{ccc}
\hline No & Yes & Yes \\
No & No & Yes \\
\hline
\end{tabular}

Control for Seat Location

Full Controls

\section{Observations}

R-squared

74971

0.0027

0.0011

74971

0.0031

74971

0.0011

0.0867

0.0011

Mean of Dep. Var.

Models with full controls include indicators for age, seating position in the vehicle, principlep

vehicle's model year, the time of the crash, whether it was on a weekend, if the speed limit was greater than $55 \mathrm{mph}$, year indicators, model year indicators, as well as indicators for missing values for the seat location, model year, time of day, and missing speed limit. Driver controls include whether the driver was belted, the degree of injury sustained by the driver, and interactions between the driver belt status and driver injuries. The omitted child restraint is child safety seat. $*=$ significant at the 0.05 level, **=significant at the 0.01 level. moderate injury

report of pain

\begin{tabular}{ccc}
$(4)$ & $(5)$ & $(6)$ \\
\hline 0.0065 & 0.0050 & 0.0043 \\
{$[0.0010]^{* *}$} & {$[0.0010]^{* *}$} & {$[0.0011]^{* *}$} \\
\hline 0.0113 & 0.0112 & 0.0068 \\
{$[0.0023]^{* *}$} & $0.0023]^{* *}$ & {$[0.0023]^{* *}$} \\
\hline 0.1005 & 0.0988 & 0.0768 \\
& \\
\hline 0.0086$]^{* *}$ & {$[0.0086]^{* *}$} & {$[0.0082]^{* *}$} \\
\hline
\end{tabular}

\begin{tabular}{ccc}
$(7)$ & $(8)$ & $(9)$ \\
\hline 0.0346 & 0.0317 & 0.0170 \\
{$[0.0023]^{* *}$} & {$[0.0023]^{* *}$} & {$[0.0023]^{* *}$} \\
\hline 0.0546 & 0.0540 & 0.0291 \\
{$[0.0049]^{* *}$} & {$[0.0050]^{* *}$} & {$[0.0048]^{* *}$} \\
\hline 0.1463 & 0.1428 & 0.0951 \\
{$[0.0111]^{* *}$} & {$[0.0112]^{* *}$} & {$[0.0106]^{* *}$} \\
\hline
\end{tabular}

\begin{tabular}{lll} 
No & Yes & Yes \\
No & No & Yes \\
\hline
\end{tabular}

$\begin{array}{llllll}74971 & 74971 & 74971 & 74971 & 74971 & 74971\end{array}$

$\begin{array}{llllll}0.0112 & 0.0118 & 0.1036 & 0.0091 & 0.0097 & 0.1317\end{array}$

1317

.0780

\begin{tabular}{ccc} 
No & Yes & Yes \\
No & No & Yes \\
\hline
\end{tabular}


Table 5: Police-Reported Injury Comparison Across Restraint Types: Wisconsin

Dependent Variable:

fatal or incapacitating

nonincapacitating

possible injury

lap \& shoulder

\begin{tabular}{ccc}
$(1)$ & $(2)$ & $(3)$ \\
\hline 0.0007 & -0.0004 & -0.0009
\end{tabular}

(4) (5)

(6)

0.0027

\begin{tabular}{ccc}
$(7)$ & $(8)$ & $(9)$ \\
\hline 0.0245 & 0.0207 & 0.0097
\end{tabular}

\begin{tabular}{|c|c|c|c|c|c|c|c|}
\hline$[0.0006]$ & {$[0.0006]$} & {$[0.0007]$} & {$[0.0014]^{* *}$} & {$[0.0015]^{*}$} & {$[0.0017]$} & {$[0.0021]^{* *}$} & {$[0.0022]^{* *}[0.0025]^{* *}$} \\
\hline 0.00 & 0.0025 & 0.0007 & 0.0114 & 0.0120 & 0.0035 & 0.0245 & 0.0250 \\
\hline
\end{tabular}

lap only

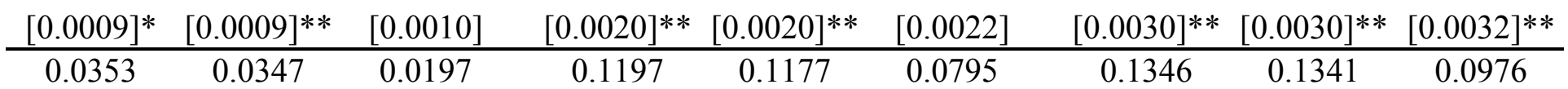

no restraint

$[0.0030]^{* *}[0.0030]^{* *}[0.0028]^{* *}[0.0053]^{* *}[0.0054]^{* *}[0.0055]^{* *}$

$[0.0061]^{* *}[0.0062]^{* *}[0.0066]^{* *}$

Control for Seat Location

Full Controls

\begin{tabular}{|c|c|c|c|c|c|c|c|c|}
\hline No & Yes & Yes & No & Yes & Yes & No & Yes & Yes \\
\hline No & No & Yes & No & No & Yes & No & No & Yes \\
\hline 76343 & 76343 & 76343 & 76343 & 76343 & 76343 & 76343 & 76343 & 76343 \\
\hline 0.0087 & 0.0091 & 0.1639 & 0.0193 & 0.0224 & 0.1102 & 0.0118 & 0.0125 & 0.1010 \\
\hline 0.0079 & 0.0079 & 0.0079 & 0.0399 & 0.0399 & 0.0399 & 0.0843 & 0.0843 & 0.0843 \\
\hline
\end{tabular}

Observations

R-squared

0.0079

.0079

.0079

0.0399

0399

0843

.0843

Models with full controls include indicators for age, seating position in the vehicle, principle point of impact, the number of vehicles in the crash, the type of vehicle, the vehicle's model year, the time of the crash, whether it was on a weekend, if the speed limit was greater than $55 \mathrm{mph}$, year indicators, model year indicators, as well as indicators for missing values for the speed limit, model year, and time of day. Driver controls include whether the driver was belted, the degree of injury sustained by the driver, interactions between the driver belt status and driver injuries, and whether the driver was at fault. The omitted child restraint is child safety seat. $*=$ significant at the 0.05 level, ${ }^{* *}=$ significant at the 0.01 level. 
Table 6: Hospital Outcomes Across Restraint Types: Wisconsin

\begin{tabular}{|c|c|c|c|c|c|c|}
\hline \multirow{3}{*}{ Dependent Variable: } & & & \multicolumn{4}{|c|}{ Conditional on Hospital Admission } \\
\hline & \multicolumn{2}{|c|}{ hospital admission } & \multicolumn{2}{|c|}{$\log$ (length of stay) } & \multicolumn{2}{|c|}{$\log ($ charges $)$} \\
\hline & $(1)$ & $(2)$ & $(3)$ & $(4)$ & $(5)$ & $(6)$ \\
\hline \multirow[t]{2}{*}{ lap \& shoulder } & -0.0001 & -0.0002 & -0.2277 & -0.4407 & -0.1914 & -0.3972 \\
\hline & {$[0.0005]$} & {$[0.0006]$} & {$[0.1390]$} & {$[0.1689]^{* *}$} & {$[0.1842]$} & [0.2161] \\
\hline \multirow[t]{2}{*}{ lap only } & 0.0013 & 0.0014 & -0.0249 & -0.2418 & -0.0350 & -0.1529 \\
\hline & {$[0.0007]$} & {$[0.0008]$} & {$[0.1756]$} & {$[0.2005]$} & {$[0.2274]$} & {$[0.2525]$} \\
\hline \multirow[t]{2}{*}{ no restraint } & 0.0249 & 0.0178 & -0.0177 & -0.2234 & -0.0745 & -0.1580 \\
\hline & {$[0.0025]^{* *}$} & {$[0.0024]^{* *}$} & {$[0.1415]$} & {$[0.2123]$} & {$[0.1770]$} & {$[0.2526]$} \\
\hline Full Controls & No & Yes & No & Yes & No & Yes \\
\hline Observations & 76343 & 76343 & 353 & 353 & 353 & 353 \\
\hline R-squared & 0.0075 & 0.0560 & 0.0111 & 0.2003 & .0039 & 0.2024 \\
\hline Mean of Dep. Var. & 0.0046 & 0.0046 & 1.383 & 1.383 & 8.789 & 8.789 \\
\hline \multicolumn{7}{|c|}{$\begin{array}{l}\text { Models with full controls include indicators for age, seating position in the vehicle, principle point of impact, the number of } \\
\text { vehicles in the crash, the type of vehicle, the vehicle's model year, the time of the crash, whether it was on a weekend, if the } \\
\text { speed limit was greater than } 55 \mathrm{mph} \text {, year indicators, model year indicators, as well as indicators for missing values for the } \\
\text { speed limit, model year, and time of day. Driver controls include whether the driver was belted, the degree of injury } \\
\text { sustained by the driver, interactions between the driver belt status and driver injuries, and whether the driver was at fault. } \\
\text { The omitted child restraint is child safety seat. }{ }^{*}=\text { significant at the } 0.05 \text { level, }{ }^{* *}=\text { significant at the } 0.01 \text { level. }\end{array}$} \\
\hline
\end{tabular}


Table 7: Accident or Vehicle Fixed Effects

\begin{tabular}{|c|c|c|c|c|c|c|}
\hline \multicolumn{7}{|l|}{ A. GES } \\
\hline \multirow[t]{2}{*}{ Dependent Variable: } & \multicolumn{2}{|c|}{ fatal or incapacitating } & \multicolumn{2}{|c|}{ nonincapacitating } & \multicolumn{2}{|c|}{ possible injury } \\
\hline & $(1)$ & $(2)$ & $(3)$ & $(4)$ & $(5)$ & $(6)$ \\
\hline \multirow[t]{2}{*}{ lap \& shoulder } & 0.0011 & 0.0022 & 0.0081 & 0.0036 & 0.0108 & 0.0098 \\
\hline & {$[0.0024]$} & {$[0.0027]$} & {$[0.0057]$} & {$[0.0061]$} & {$[0.0095]$} & {$[0.0101]$} \\
\hline \multirow[t]{2}{*}{ lap only } & -0.0007 & -0.0007 & 0.0134 & 0.0111 & 0.0139 & 0.0153 \\
\hline & {$[0.0024]$} & {$[0.0027]$} & {$[0.0065]^{*}$} & {$[0.0070]$} & {$[0.0110]$} & {$[0.0112]$} \\
\hline \multirow[t]{2}{*}{ no restraint } & 0.0148 & 0.0103 & 0.0434 & 0.0369 & 0.0586 & 0.0536 \\
\hline & {$[0.0068]^{*}$} & {$[0.0070]$} & {$[0.0126]^{* *}$} & {$[0.0135]^{* *}$} & {$[0.0180]^{* *}$} & {$[0.0202]^{* *}$} \\
\hline Accident Fixed Effects & Yes & No & Yes & No & Yes & No \\
\hline Vehicle Fixed Effects & No & Yes & No & Yes & No & Yes \\
\hline Observations & 17779 & 16111 & 17779 & 16111 & 17779 & 16111 \\
\hline R-squared & 0.8343 & 0.8441 & 0.6895 & 0.7041 & 0.7641 & 0.7862 \\
\hline Mean of Dep. Var. & 0.0178 & 0.0183 & 0.0468 & 0.0476 & 0.0934 & 0.095 \\
\hline
\end{tabular}

\section{B. New Jersey}

Dependent Variable: fatal or incapacitating moderate injury report of pain

\begin{tabular}{lcccccc} 
& $(1)$ & $(2)$ & $(3)$ & $(4)$ & $(5)$ & $(6)$ \\
\cline { 2 - 7 } lap \& shoulder & 0.0005 & 0.0009 & 0.0009 & 0.0011 & 0.0067 & 0.0090 \\
& {$[0.0007]$} & {$[0.0007]$} & {$[0.0034]$} & {$[0.0037]$} & {$[0.0062]$} & {$[0.0067]$} \\
\cline { 2 - 7 } lap only & 0.0019 & 0.0002 & 0.0085 & 0.0179 & -0.0055 & 0.0027 \\
& {$[0.0013]$} & {$[0.0004]$} & {$[0.0068]$} & {$[0.0071]^{*}$} & {$[0.0100]$} & {$[0.0109]$} \\
\cline { 2 - 7 } no restraint & 0.0102 & 0.0010 & 0.0563 & 0.0916 & 0.0678 & 0.0622 \\
& {$[0.0067]$} & {$[0.0008]$} & {$[0.0243]^{*}$} & {$[0.0263]^{* *}$} & {$[0.0264]^{*}$} & {$[0.0299]^{*}$} \\
\cline { 2 - 7 } & & No & Yes & No & Yes & No \\
Accident Fixed Effects & Yes & Yes & No & Yes & No & Yes \\
\cline { 2 - 7 } Vehicle Fixed Effects & No & Yes & 23695 & 27236 & 23695 \\
Observations & 27236 & 23695 & 27236 & 23695 & 0.7603 \\
R-squared & 0.6177 & 0.6675 & 0.6745 & 0.7147 & 0.7249 & 0.0696 \\
Mean of Dep. Var. & 0.0009 & 0.0008 & 0.0161 & 0.0161 & 0.0709 & 0.069 \\
\hline
\end{tabular}

\section{Wisconsin}

Dependent Variable: fatal or incapacitating nonincapacitating possible injury

\begin{tabular}{lcccccc} 
& $(1)$ & $(2)$ & $(3)$ & $(4)$ & $(5)$ & $(6)$ \\
\cline { 2 - 7 } lap \& shoulder & -0.0005 & -0.0012 & -0.0010 & -0.0036 & 0.0014 & 0.0016 \\
& {$[0.0015]$} & {$[0.0015]$} & {$[0.0042]$} & {$[0.0045]$} & {$[0.0053]$} & {$[0.0056]$} \\
\cline { 2 - 7 } lap only & -0.0010 & -0.0015 & -0.0056 & -0.0076 & 0.0116 & 0.0137 \\
& {$[0.0020]$} & {$[0.0018]$} & {$[0.0051]$} & {$[0.0055]$} & {$[0.0068]$} & {$[0.0072]$} \\
\cline { 2 - 7 } no restraint & 0.0155 & 0.0156 & 0.0692 & 0.0768 & 0.0765 & 0.0697 \\
& {$[0.0055]^{* *}$} & {$[0.0066]^{*}$} & {$[0.0149]^{* *}$} & {$[0.0170]^{* *}$} & {$[0.0181]^{* *}$} & {$[0.0204]^{* *}$} \\
\cline { 2 - 7 } Accident Fixed Effects & Yes & No & Yes & No & Yes & No \\
\cline { 2 - 7 } Vehicle Fixed Effects & No & Yes & No & Yes & No & Yes \\
\cline { 2 - 7 } Observations & 30974 & 28310 & 30974 & 28310 & 30974 & 28310 \\
R-squared & 0.7350 & 0.7456 & 0.6607 & 0.6762 & 0.7174 & 0.7388 \\
Mean of Dep. Var. & 0.0071 & 0.0072 & 0.0356 & 0.0359 & 0.0780 & 0.0784 \\
\hline
\end{tabular}

Data are restricted to accidents (vehicles) with more than one child present in the accident (vehicle) fixed effects specifications. All models are estimated with the full set of controls not absorbed by the fixed effects, including indicators for age, sex, and seat location in the vehicle fixed effects specifications, as well as model year, point of impact, vehicle type, and driver controls in the accident fixed effects specifications. The omitted child restraint is child safety seat. Sampling weights in the GES data are applied to calculate nationally representative statistics. ${ }^{*}=$ significant at the 0.05 level, ${ }^{* *}=$ significant at the 0.01 level. 
Table 8: Comparisons Across Subgroups in the GES

A. Dependent Variable: fatal or incapacitating

\begin{tabular}{|c|c|c|c|c|c|c|c|c|c|c|}
\hline & $\begin{array}{c}\text { baseline } \\
(1)\end{array}$ & $\begin{array}{l}\text { no fault } \\
\text { (2) }\end{array}$ & $\begin{array}{l}\text { rear/side } \\
\text { impact } \\
(3)\end{array}$ & $\begin{array}{c}\text { age } 2 \\
(4)\end{array}$ & $\begin{array}{c}\text { age } 4 \\
(5)\end{array}$ & $\begin{array}{c}\text { age } 6 \\
(6)\end{array}$ & $\begin{array}{c}\text { back seat } \\
(7)\end{array}$ & $\begin{array}{c}\text { Model Yr } \\
>=1997 \\
(8)\end{array}$ & $\begin{array}{c}\text { Crash Yr } \\
>=1997 \\
(9)\end{array}$ & $\begin{array}{c}\text { car only } \\
(10)\end{array}$ \\
\hline \multirow{2}{*}{ lap \& shoulder } & 0.0015 & 0.0009 & 0.0014 & 0.0043 & -0.0035 & 0.0040 & 0.0001 & 0.0019 & 0.0020 & 0.0013 \\
\hline & {$[0.0013]$} & {$[0.0016]$} & {$[0.0015]$} & {$[0.0026]$} & {$[0.0025]$} & {$[0.0036]$} & [0.0013] & [0.0019] & {$[0.0015]$} & {$[0.0016]$} \\
\hline \multirow[t]{2}{*}{ lap only } & 0.0034 & 0.0039 & 0.0051 & 0.0009 & -0.0030 & 0.0083 & 0.0032 & 0.0034 & 0.0035 & 0.0034 \\
\hline & {$[0.0014]^{*}$} & {$[0.0018]^{*}$} & {$[0.0018]^{* *}$} & {$[0.0030]$} & {$[0.0029]$} & {$[0.0042]^{*}$} & {$[0.0015]^{*}$} & {$[0.0030]$} & {$[0.0020]$} & {$[0.0018]$} \\
\hline \multirow[t]{2}{*}{ no restraint } & 0.0265 & 0.0210 & 0.0187 & 0.0365 & 0.0178 & 0.0237 & 0.0244 & 0.0306 & 0.0310 & 0.0240 \\
\hline & {$[0.0030]^{* *}$} & {$[0.0038]^{* *}$} & {$[0.0035]^{* *}$} & {$[0.0070]^{* *}$} & {$[0.0058]^{* *}$} & {$[0.0071]^{* *}$} & {$[0.0032]^{* *}$} & {$[0.0108]^{* *}$} & {$[0.0054]^{* *}$} & {$[0.0035]^{* *}$} \\
\hline Obser & & & & & 9 & & & 86 & & \\
\hline R-squared & 0.2791 & 0.2674 & 0.2893 & 0.276 & 0.3178 & 0.339 & & 0.3063 & 0.2866 & 0.2911 \\
\hline Mean of Dep. Var. & 0.0201 & 0.0143 & 0.0153 & 0.0178 & 0.0214 & 0.0223 & 0.0169 & 0.0115 & 0.0178 & 0.0212 \\
\hline
\end{tabular}

B. Dependent Variable: nonincapacitating injury

\begin{tabular}{|c|c|c|c|c|c|c|c|c|c|c|}
\hline & $\begin{array}{c}\text { baseline } \\
\text { (1) }\end{array}$ & $\begin{array}{l}\text { no fault } \\
\text { (2) }\end{array}$ & $\begin{array}{c}\text { rear/side } \\
\text { impact } \\
\text { (3) }\end{array}$ & $\begin{array}{l}\text { age } 2 \\
(4)\end{array}$ & $\begin{array}{l}\text { age } 4 \\
(5)\end{array}$ & $\begin{array}{c}\text { age } 6 \\
(6)\end{array}$ & $\begin{array}{l}\text { back seat } \\
\text { (7) }\end{array}$ & $\begin{array}{c}\text { Model Yr } \\
>=1997 \\
\text { (8) }\end{array}$ & $\begin{array}{c}\text { Crash Yr } \\
>=1997 \\
\text { (9) }\end{array}$ & $\begin{array}{l}\text { car only } \\
\text { (10) }\end{array}$ \\
\hline \multirow[t]{2}{*}{ lap \& shoulder } & 0.0014 & 0.0026 & 0.0001 & -0.0019 & 0.0038 & -0.0094 & 0.0021 & -0.0010 & 0.0024 & 0.0000 \\
\hline & {$[0.0023]$} & {$[0.0033]$} & {$[0.0030]$} & {$[0.0050]$} & {$[0.0042]$} & {$[0.0117]$} & {$[0.0025]$} & {$[0.0039]$} & {$[0.0029]$} & {$[0.0030]$} \\
\hline \multirow[t]{2}{*}{ lap only } & 0.0093 & 0.0049 & 0.0060 & 0.0093 & 0.0143 & 0.0080 & 0.0046 & 0.0097 & 0.0118 & 0.0076 \\
\hline & {$[0.0028]^{* *}$} & [0.0037] & [0.0037] & {$[0.0070]$} & {$[0.0051]^{* *}$} & {$[0.0125]$} & [0.0029] & {$[0.0069]$} & {$[0.0041]^{* *}$} & {$[0.0035]^{*}$} \\
\hline \multirow[t]{2}{*}{ no restraint } & 0.0558 & 0.0363 & 0.0340 & 0.0487 & 0.0745 & 0.0381 & 0.0388 & 0.0504 & 0.0626 & 0.0550 \\
\hline & {$[0.0051]^{* *}$} & {$[0.0075]^{* *}$} & {$[0.0065]^{* *}$} & {$[0.0109]^{* *}$} & {$[0.0112]^{* *}$} & {$[0.0159]^{*}$} & {$[0.0054]^{* *}$} & {$[0.0160]^{* *}$} & {$[0.0081]^{* *}$} & {$[0.0062]^{* *}$} \\
\hline Obser & & & & & & & & o & & \\
\hline R-squared & 0.1239 & 0.1105 & 0.1155 & 0.1361 & 0.1305 & 0.1343 & 0.1122 & 0.1246 & 0.1188 & 0.1173 \\
\hline Mean of Dep. Var. & 0.0518 & 0.0381 & 0.0399 & 0.0462 & 0.049 & 0.0598 & 0.043 & 0.032 & 0.0437 & 0.0552 \\
\hline
\end{tabular}

\section{Dependent Variable: possible injury}

\begin{tabular}{|c|c|c|c|c|c|c|c|c|c|c|}
\hline & $\begin{array}{c}\text { baseline } \\
\text { (1) }\end{array}$ & $\begin{array}{l}\text { no fault } \\
\text { (2) }\end{array}$ & $\begin{array}{c}\text { rear/side } \\
\text { impact } \\
(3)\end{array}$ & $\begin{array}{c}\text { age } 2 \\
(4)\end{array}$ & $\begin{array}{c}\text { age } 4 \\
(5)\end{array}$ & $\begin{array}{l}\text { age } 6 \\
(6)\end{array}$ & $\begin{array}{c}\text { back seat } \\
(7)\end{array}$ & $\begin{array}{c}\text { Model Yr } \\
>=1997 \\
(8)\end{array}$ & $\begin{array}{c}\text { Crash Yr } \\
>=1997 \\
(9)\end{array}$ & $\begin{array}{c}\text { car only } \\
(10)\end{array}$ \\
\hline \multirow[t]{2}{*}{ lap \& shoulder } & 0.0183 & 0.0148 & 0.0150 & 0.0382 & 0.0002 & 0.0234 & 0.0186 & 0.0343 & 0.0205 & 0.0159 \\
\hline & {$[0.0043]^{* *}$} & {$[0.0070]^{*}$} & {$[0.0063]^{*}$} & {$[0.0092]^{* *}$} & [0.0091] & {$[0.0158]$} & {$[0.0048]^{* *}$} & {$[0.0088]^{* *}$} & {$[0.0056]^{* *}$} & {$[0.0055]^{* *}$} \\
\hline \multirow[t]{2}{*}{ lap only } & 0.0170 & 0.0087 & 0.0073 & 0.0132 & 0.0117 & 0.0156 & 0.0151 & 0.0034 & 0.0131 & 0.0151 \\
\hline & {$[0.0049]^{* *}$} & {$[0.0081]$} & {$[0.0072]$} & [0.0099] & {$[0.0104]$} & {$[0.0175]$} & {$[0.0053]^{* *}$} & {$[0.0120]$} & {$[0.0072]$} & {$[0.0060]^{*}$} \\
\hline \multirow[t]{2}{*}{ no restraint } & 0.0476 & 0.0334 & 0.0317 & 0.0297 & 0.0464 & 0.0479 & 0.0419 & 0.0500 & 0.0414 & 0.0501 \\
\hline & {$[0.0071]^{* *}$} & {$[0.0122]^{* *}$} & {$[0.0106]^{* *}$} & {$[0.0132]^{*}$} & {$[0.0166]^{* *}$} & {$[0.0228]^{*}$} & {$[0.0083]^{* *}$} & {$[0.0204]^{*}$} & {$[0.0112]^{* *}$} & {$[0.0088]^{* *}$} \\
\hline Obser & 205 & 18 & 23251 & 98 & 97 & 80 & & 8698 & & \\
\hline R-squared & 0.1287 & 0.1219 & 0.122 & 0.1288 & 0.135 & 0.1348 & 0.1263 & 0.143 & 0.1265 & 0.1273 \\
\hline Mean of Dep. Var. & 0.1058 & 0.1109 & 0.109 & 0.0833 & 0.1101 & 0.1236 & 0.0994 & 0.0911 & 0.1013 & 0.1137 \\
\hline
\end{tabular}

Models use GES data, weighted to calculate nationally representative statistics. All models are estimated with the full set of controls. The omitted child restraint is child si seat. $*=$ significant at the 0.05 level, $* *=$ significant at the 0.01 level. 